\title{
Fabrication of low cost perovskite solar cell under ambient conditions using only spin coating deposition method
}

\author{
Michael Hariadi ${ }^{1}$, Istighfari Dzikri ${ }^{1}$, Retno Wigajatri Purnamaningsih ${ }^{1}$, Nji Raden Poespawati ${ }^{1}$. \\ ${ }^{1}$ Department of Electrical Engineering, Faculty of Engineering, Universitas Indonesia, Depok 16424, Indonesia
}

\begin{abstract}
Indonesia is an archipelagic nation that has many small islands where the average load is low and currently supplied by diesel power generators. The drawbacks from these generators are cost constraints from its operation. Solar cells are the solution of this problem with the support of daily average radiation in Indonesia of $4.8 \mathrm{kWh} / \mathrm{m}^{2} /$ day. There has been a lot of technology for the construction of solar cells such as silicon based, copper indium gallium selenide (CIGS), which was already successfully commercialized. However, these technologies have been obsolete and started to reach its maximum potential. Perovskite solar cells have a very high future potential, due to the increase on the efficiency of this technology in a relatively short amount of time. The current challenge for the fabrication of perovskite solar cell is the material cost and fabrication cost. This paper discussed the low-cost fabrication of perovskite solar cell using only spin coating deposition method and relatively also low-cost materials for the structure of the perovskite solar cell itself. As a result, we achieve perovskite solar cell with Voc of $0.6 \mathrm{~V}$, Isc of $13 \mathrm{~mA}$, FF of 0.28 , and $1.2 \%$ efficiency.
\end{abstract}

\section{Introduction}

One of the best alternative renewable energy is solar energy utilization. The solar cells can solve the problem experienced by diesel power plant in Indonesia. Since 2009 , the cost to generate the same power as diesel power plant was more efficient by using solar power plant. After 2015, solar power plant has surpassed the efficiency of the steam power plant especially on the ongrid system. Therefore, solar cells can solve a lot of energy and environment problems in Indonesia ${ }^{[1]}$.

Perovskite solar cells are a third generation of solar cells utilizing organic-metal halide perovskite materials, such as $\mathrm{MAPbX}_{3}\left(\mathrm{MA}=\mathrm{CH}_{3} \mathrm{NH}_{3}{ }^{+} ; \mathrm{X}=\mathrm{Cl}^{-}, \mathrm{Br}^{-}, \mathrm{I}^{-}\right)$as the light absorber. They have recently enticing due to its efficiency rating in the last four years ${ }^{[2]}$. Despite of the research conducted still at a laboratory scale, perovskite solar cell has promising development as the light absorber for third generation of solar cells. perovskite solar cell features a large band gap, large absorption coefficient, high carrier mobility, long carrier diffusion length and small binding energy ${ }^{[3]-[7]}$. By having these features, perovskite solar cell should be able to compete with conventional silicon-based solar cells and have become a new direction for developing high efficiency solar cells ${ }^{[8]}$.

There are variety of techniques for depositing thin layers on perovskite solar cell such as physical vapor deposition, metal-organic chemical vapor deposition, and molecular beam epitaxy. However, these methods have drawbacks in coating uniformity and efficiency is made. On the other hand, the method of pulsed laser deposition and sputtering have weaknesses in control and replication capabilities, when compared with other techniques ${ }^{[9]}$, Spin-coating method can produce uniform deposition of thin layers on broad layers. This method has many advantages such as ${ }^{[9]}$ : The flexibility to control the thickness of the layer through the rotational speed and viscosity of the solution, the process at a low temperature, is compatible with flexible substrates.

Current high-performance perovskite solar cell uses expensive metals such as gold as its cathode and use expensive hole transport materials (HTM) such as SpiroOMeTAD ${ }^{[10]}$. However, these materials have relatively high cost both for the fabrication processes and the material itself. The highest efficiency of perovskite solar cell devices also came by performing both fabrication and characterization under extremely low humidity in a glove box. The use of glove box is not efficient from the industrial point of view. Therefore, it is crucial to explore both the preparation of the perovskite solar cell and their characterization under ambient condition as this is a relevant aspect for the future mass production [11].

In this research, we had fabricated low-cost perovskite solar cells under ambient conditions and found the best electrical characteristics from a few perovskite solar cell devices measured.

\footnotetext{
*Corresponding author: pupu@eng.ui.ac.id
} 


\section{Methodology}

\subsection{Materials}

Each precursor for each layer of the device was fabricated a day before the perovskite solar cell fabrication itself. MAPbI3 was synthesized by mixing $140 \mathrm{mg} \quad \mathrm{PbCl}_{2}, \quad 240 \mathrm{mg} \quad \mathrm{CH}_{3} \mathrm{NH}_{3} \mathrm{I}$ and $1 \mathrm{ml}$ Dimethylformamide (DMF). $\mathrm{TiO}_{2}$ was synthesized by mixing $5 \mathrm{ml} \mathrm{C}_{2} \mathrm{H}_{6} \mathrm{O}, 0.3 \mathrm{ml}$ TTIP and $0.1 \mathrm{ml} \mathrm{HCl}$. Meanwhile CuSCN was synthesized by dissolving $6 \mathrm{mg}$ of CuSCN and $1 \mathrm{~mL}$ Dipropylsulfide (DPS) ${ }^{[12]}$.

\subsection{Device Structure}

In this research, fabricated perovskite solar cells will consist of an anode layer, ETL, the active layer, HTL, and the cathode. Figure 1 illustrates the structure of the solar cells which will be made.

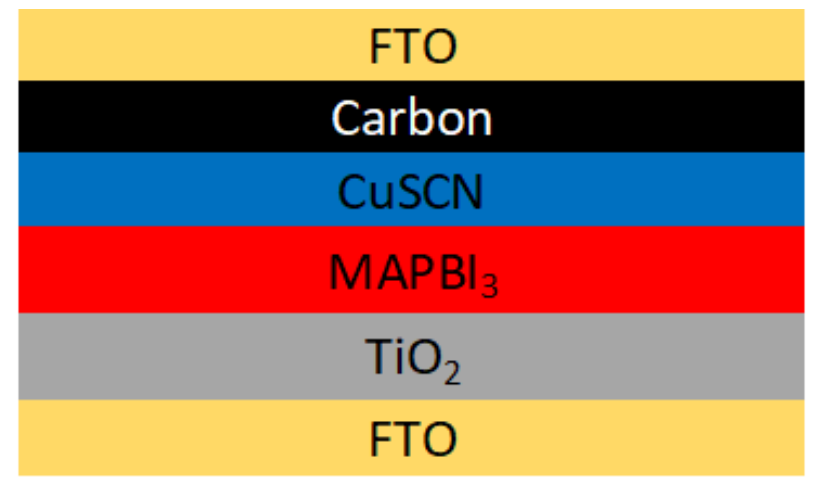

Fig 1. Structure of the Fabricated Solar Cells

On cathode layer we use FTO conductive glass with energy level of $-4.4 \mathrm{eV}$, for electron transport materials (ETM) we use $\mathrm{TiO}_{2}$ with energy level of its conduction band $-4 \mathrm{eV}$. For the active layer we used $\mathrm{MAPbI}_{3}$ with band gaps ranging from -3.93 to $-5.43 \mathrm{eV}$. For HTM we used CuSCN with valence band of $-5.3 \mathrm{eV}$. Finally, for cathode we use carbon powder and FTO glass with valence band of -5 and -4.4 respectively [13][15]. The energy diagram from this arrangement can be seen on Figure 2.

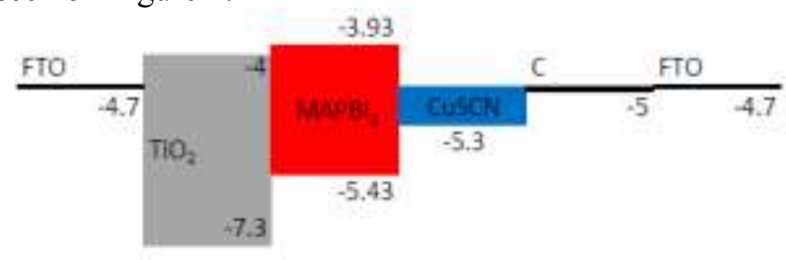

Fig 2. Energy level $(\mathrm{eV})$ of each layers from the fabricated solar cells.

\subsection{Fabrication Processes}

The first step of fabrication processes was preparing FTO glass $(2 \mathrm{~cm} \times 2 \mathrm{~cm})$, and determined its conducting side using multimeter. FTO glass cleaning is done in three stages: distilled water, acetone, and ethanol. Each stage is conducted inside ultrasonic cleaning devices for 5 minutes.

$\mathrm{TiO}_{2}$ layer deposition was conducted using spin coating and annealing on a hot plate in the second step of fabrication process. A quarter of the conductive substrate side is closed by using masking tape. $\mathrm{TiO} 2$ solution will be dropped on top of the conductive side until it covers all area and then it was performed spin coating at 1000 rpm for 30 seconds. Subsequently the masking tape was removed, thereafter put the substrate to hotplate for annealing process at $425^{\circ} \mathrm{C}$ for 30 minutes. After 30 minutes the heat source is turn and wait until the substrate cools down to ambient temperature for approximately 20 minutes before proceeds to the next step. The illustration for this second step of fabrication processes can be seen on Figure 3.

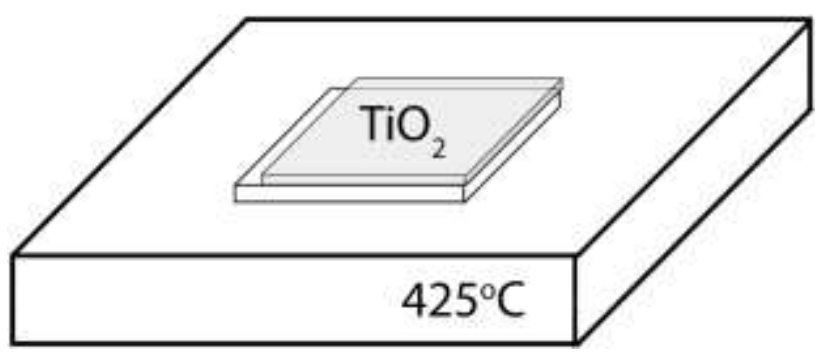

Fig 3. Procedure of deposit $\mathrm{TiO}_{2}$ layer on a FTO glass plate, covering $3 / 4$ of its surface.

$\mathrm{MAPbI}_{3}$ layer deposition was conducted using spin coating and annealing on a hot plate in the third step. A quarter of the conductive substrate side was closed by using heat resistant tape. Then $\mathrm{MAPbI}_{3}$ solution was dropped on top of the conductive side until it covers all area. Thereafter it was undertaken spin coating at 1000 rpm for 30 seconds. The masking tape should not be removed, afterward assigned the substrate to hotplate for annealing process at $120^{\circ} \mathrm{C}$ for 30 minutes. After 30 minutes the heat source is rotated and wait until the substrate cools down to ambient temperature for approximately 10 minutes before proceeds to the next step. This third step of fabrication processes can be illustrated on Figure 4.

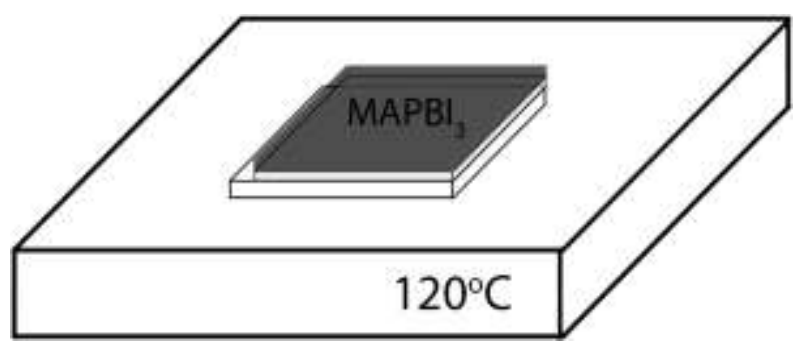

Fig 4. $\mathrm{MAPbI}_{3}$ layer deposit procedure on a $\mathrm{FTO} / \mathrm{TiO}_{2}$ film.

The fourth step of fabrication process was $\mathrm{CuSCN}$ layer deposition. It was conducted using spin coating and annealing on a hot plate. The $\mathrm{TiO} 2$ solution was dropped on top of the conductive side until it covers all area. Then it was performed spin coating at $500 \mathrm{rpm}$ for 30 seconds. After that the masking tape was removed, then put the substrate to hotplate for annealing process at 
$80^{\circ} \mathrm{C}$ for 15 minutes. After 15 minutes the heat source is turn and wait until the substrate cools down to ambient temperature for approximately 5 minutes. The illustration for this fourth step of fabrication processes can be shown on Figure 5.

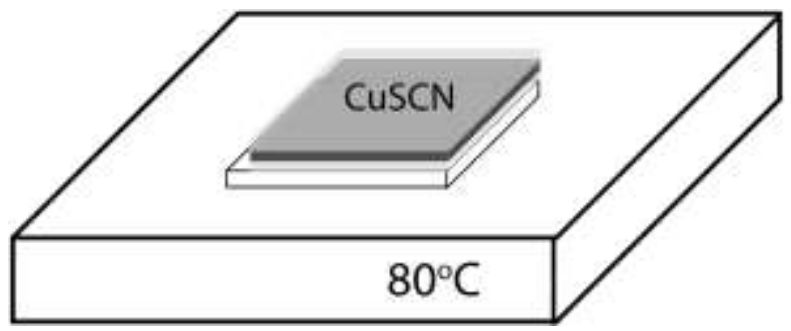

Fig 5. Procedure of deposit $\mathrm{CuSCN}$ layer on a $\mathrm{FTO} / \mathrm{TiO}_{2} /$ $\mathrm{MAPbI}_{3}$ film.

Carbon layer deposition was done by sprinkling powdered carbon on top of the cathode FTO glass in the fifth step of fabrication process. A quarter of the conductive substrate side is closed by using masking tape. Powdered carbon was sprinkled on top of the FTO conductive side. The carbon powder layer is flatted to form a thin uniform layer. Powdered carbon is added more if necessary to improve the quality of the coating. The fifth step of fabrication processes can be seen on Figure 6.

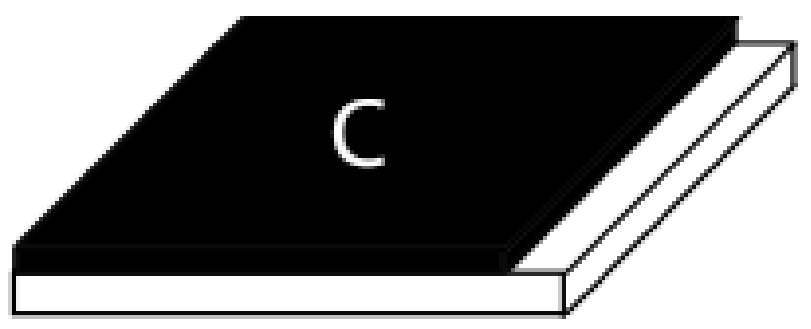

Fig 6. Carbon Powder deposit procedure on a FTO glass plate, covering $3 / 4$ of its surface.

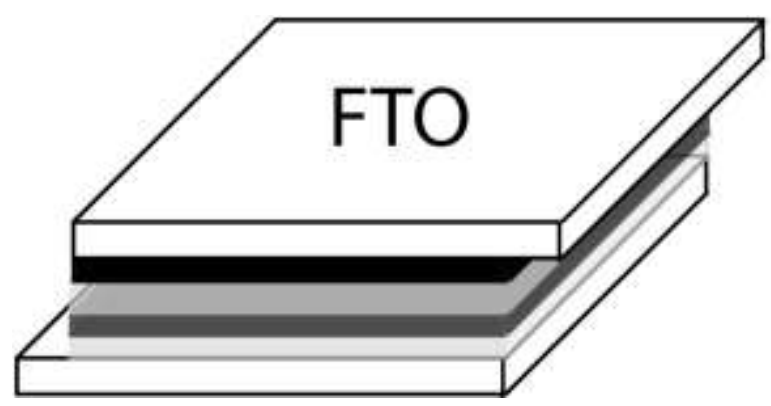

Fig 7. Perovskite solar cell structure post fabrication processes.

After performing deposition of thin layers for cathode and anode, the next step was combine the two pieces of glasses. The anode and cathode are combined by attaching both conductive sides with the deposited parts on top of each other. Figure 7 shows the illustration of how the devices arranged on top of each other. We used transparent tape to stick both glasses so that they do not move easily and have a good contact in between.
Binder clips also feasible for this application but the clips might be block some of the area of the perovskite solar cell and may reduce the performance of the device.

\section{Results and Discussion}

In this research has been carried out by three variables fabrication spin coating perovskite active layer of the solar cell. The comparison of all the electrical parameters from three variables fabrication can be seen on Table 1. Meanwhile the comparison of all I-V curves of the variables can be seen on Figure 8.

Table 1. The comparison of Electrical parameters of all three fabricated variables perovskite solar cell.

\begin{tabular}{|c|c|c|c|}
\hline $\begin{array}{c}\text { Electrical } \\
\text { Parameters }\end{array}$ & $\begin{array}{c}\text { Spin } \\
\text { Coating } \\
500 \mathrm{rpm}\end{array}$ & $\begin{array}{c}\text { Spin } \\
\text { Coating } \\
1000 \mathrm{rpm}\end{array}$ & $\begin{array}{c}\text { Spin } \\
\text { Coating } \\
2000 \mathrm{rpm}\end{array}$ \\
\hline $\mathrm{V}_{\mathrm{OC}}(\mathrm{V})$ & 0.05 & 0.6 & 0.2 \\
\hline $\mathrm{I}_{\mathrm{SC}}(\mathrm{mA})$ & 1 & 13 & 1.7 \\
\hline $\mathrm{FF}$ & 0.28 & 0.27 & 0.28 \\
\hline$\eta(\%)$ & 0.006 & 1.2 & 0.04 \\
\hline
\end{tabular}

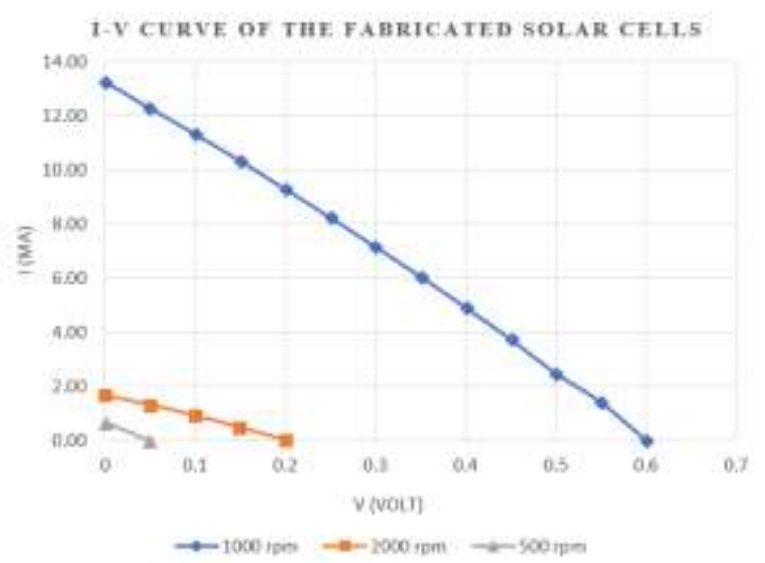

Fig 8. I-V Curves of the three fabricated variables perovskite solar cell where the blue line is $1000 \mathrm{rpm}$ variable, orange is $2000 \mathrm{rpm}$ variable and grey is $500 \mathrm{rpm}$ variable.

Variations in the speed of spin coating directly affect the thickness of the active layer obtained from perovskite solar cells. In solar cells, the overall efficiency in absorbing solar photons is a crucial aspect of improving the performance of solar cells. Increasing the thickness of the active layer can increase the level of efficiency of the solar cell light absorption, but it also can be poor if it is too thick. To increase the probability of absorption of solar energy, the incoming light into solar cells must be reflected internally to successfully absorb perfectly ${ }^{[7]}$.

In Figure 8 it is shown that perovskite solar cells by spin coating speed of $1000 \mathrm{rpm}$ at the time of the active layer deposition has the best performance, followed by a speed of $2000 \mathrm{rpm}$, and $500 \mathrm{rpm}$. When it is seen from the performance of solar cells produced by variations of $2000 \mathrm{rpm}$ can be concluded that at this rotational speed the $\mathrm{MAPbI}_{3}$ layer thickness is too thin. Variations in speed of $500 \mathrm{rpm}$ should have a relatively thick thickness that may still be in the optimal range MAPbI3 
layer thickness. However, at the time of fabrication variations, perovskite solution used by researchers never dry out and change colour to black as happens in other variations. This is most likely the reason why the electrical performance of solar cells on these variables is less good. The physical appearance after the deposition of the $\mathrm{MAPbI}_{3}$ can be seen on Figure 9.

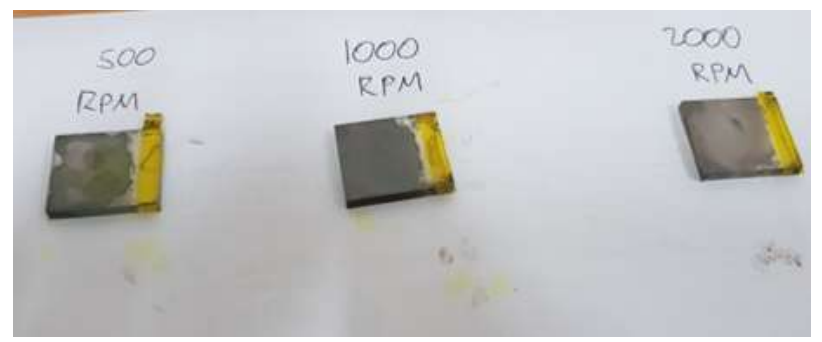

Fig 9. The condition of device after $\mathrm{MAPbI}_{3}$ deposition.

Fill factor produced by three variables spin coated with three variations of speed is not much different. All three devices have the same relatively poor fill factor. The quality of the fill factor of a solar cell is influenced by the series resistance and shunt resistance on the solar cell itself. High series resistance could result lower fill factor meanwhile low shunt resistance could also result lower fill factor of the devices.

In the case of series resistance, contact between HTM and cathode of the perovskite solar cell greatly influences the series resistance of the device. In other research in which efficiency exceeds $15 \%$, the used cathode was a contact metal such as gold, platinum, and other expensive materials. The deposition techniques for these materials are much more complicated but the result is much better in term of uniformity and the contact between layers. In this paper, we used carbon powder and FTO as a cathode because of limited equipment and materials in the laboratory and to achieve lower cost for the fabrication process. The result of this research implementation, our device has relatively high series resistance that directly contributes to the value of the poor fill factor.

In addition, low shunt resistance in this research also contributes to the relatively low fill factor value. This is caused by imperfections during the manufacturing process. In this paper, the researchers conducted laboratory fabrication is relatively simple environment, without the help of the glove box, clean room conditions and high relative humidity values. Such laboratory conditions are unfavourable for perovskite solar cell fabrication because the deposition processes at the nanometre scale and the perovskite material is sensitive to moist air, clean room conditions and low humidity values are required to fabricate high-performance perovskite solar cell.

\section{Conclusion}

Based on the results of the research, it can be concluded that low-cost perovskite solar cells can be fabricated under ambient conditions with the drawback poor fill factor value and the best spin coating speed for the
$\mathrm{MAPbI}_{3}$ layer from our experiment is $1000 \mathrm{rpm}$. We achieve perovskite solar cell with $\mathrm{V}_{\mathrm{OC}}=0.6 \mathrm{~V}, \mathrm{I}_{\mathrm{SC}}=13$ $\mathrm{mA}, \mathrm{FF}=0.28, \eta=1.2 \%$.

This work has been supported by International publications indexed for the Final Project of Students (PITTA) Research Grant 2018 from Universitas Indonesia with $\mathrm{Nr}$. 2502/UN2.R3.1/HKP.05.00/2018

\section{References}

1. PT Pembangkitan Jawa Bali, Perkenalan PLTS Cirata $1 M W$, Cirata : PT Pembangkitan Jawa Bali, (2017)

2. National Renewable Energy Lab, NREL Efficiency Chart, USA, 2017.

3. P. P. Boix, K. Nonomura, N. Mathews, and S. G. Mhaisalkar. Current progress and future perspectives for organic/inorganic perovskite solar cells, Mater. Today, Vol. 17, No. 1, Pp. 16-23, (2014)

4. S. Kazim, M. K. Nazeeruddin, M. Gratzel, and S. Ahmad, Perovskite as light harvester: A game changer in photovoltaics, Angew, Chem. Int. Ed., vol. 53, no. 11, pp. 2812-2824, (2014).

5. P. Gao, M. Gratzel, and M. K. Nazeeruddin, Organohalide lead perovskites for photovoltaic applications, Energy Environ. Sci., vol. 7, no. 8, pp. 2448-2463, (2014)

6. K. Tanaka, T. Takashi, T. Ban, T. Kondo, K. uchida, and N. Miura, Comparative study on the excitons in lead-halide-based perovskite-type crystals CH3NH3PbBr3 Ch3NH3PbI3, Solid State Commun., vol. 127, pp. 619-623, (2003).

7. M. -H. Li, P.-S. Shen, K. -C. Wang, T. -F. Guoabc, and P. Chen, Inorganic p-type contact materials for perovskite-based solar cells, J. Mater. Chem. A, vol. 3, no. 17, pp. 9011-9019 Jan. 2015.

8. A. Zhang, Y. Chen, J. Yan, Optimal design and simulation of high performance organic-metal halide perovskite solar cells, IEEE journal of quantum electronics, vol. 52, no. 6, (2016)

9. M. Ohring. Materials Science of Thin Films. Vik 8. Academic Press, pp.729-733 (2002).

10. Z. Kaddachi, M. Belhi, M. B. Kaoui and R. Gharbi. Design and Development of Spin Coating System. Science and techniques of automatic control. Tunisia. (2016).

11. A. D. Maria, V. La Ferrara, L. V. Mercaldo, E. Bobeico, T. Di Luccio and P. D. Veneri, Solutionprocessed perovskite thin films for planar solar cells under ambient conditions, IEEE conference, (2016)

12. S. Patwardhan, Introducing perovskite solar cells to undergraduates, ACS publications, pp.251-255, (2015)

13. N. -G. Park, Perovskite solar cells: an emerging photovoltaic technology, Materials today, vol. 18, no. 2, pp. 65-72, (2015)

14. H. Wang, X. Hu and $\mathrm{H}$. Chen, The efficient of carbon black in carbon counter electrode for CH3NH3PbI3/TiO2 heterojunction solar cells, RSC publishing, (2015). 
15. Yakung Song, et al, Energy level tuning of TPBbased hole-transporting materials for high efficient perovskite solar cells, Royal society of chemistry, (2014). 